\title{
Janus Clinical Trials Repository Model
}

National Cancer Institute

\section{Source}

National Cancer Institute. Janus Clinical Trials Repository Model. NCI Thesaurus. Code C142594.

The design for a standards-based infrastructure to support the receipt, validation, storage, and analysis of clinical trial data at the US Food and Drug Administration. 